\title{
Possible Pollution Threat to the Green Buffer Zone around TAJ MAHAL
}

\author{
Nilanjana Chakrabarti, Arup Kumar Mitra \\ Postgraduate Department of Microbiology, St. Xavier's College 30, Park Street, Kolkata 700016 India
}

\begin{abstract}
The Taj Mahal is situated at the banks of Yamuna River in the city of Agra. While the Taj Mahal stands with its heritage and speechless glamour, the city of Agra has been growing with a pack of industries since independence. From leather tanneries, dairy farms to marble goods, it has developed a huge number of industries, which have deliberately added on to the polluted air of the city. Several studies have reported that the white marble of the Taj Mahal is diseased with 'Stone cancer', caused by the presence of harmful NOX, SOX, chromium as well as other heavy metal pollutants present in the air surrounding it. Green vegetation, known to absorb harmful pollutants from the air has been planted around the monument to create a 'Buffer Zone' as a measure to combat the disease. But in the experiments conducted in this study it has been found that 'Anthropogenic Factors' are equally harmful to the trees as it enhances the development of infection in the leaves. The tree Mahogany and Mimusops elangi was found to populate the buffer zone frequently which may be upto 50-55\%. Hence the infection prevailing in them was studied and it was found to be Mycosphaerella and Cladosporium, causing leaf spot disease with around 45\% infection in case of high SPM content (varying approximately between 60-80\%). In an artificial stimulated condition with NOx, the infection increased upto $30 \%$, which indicated the acid tolerance and virulence of the fungal pathogen under the effect of acid vapors from different sources and infection could occur even at a high $\mathrm{pH}$ of 5.5-5.9. The niche of acidophilic fungi can substantially be reduced by Blitox treatment as tested by reduction in fungal spore count germination by $80 \%$ revealed in slide bioassay. So it may be safely concluded that relatively less important timber producing trees and fungicide dusting can effectively restore the social forest belt around Taj Mahal and thereby protect the monument in the long run.
\end{abstract}

Keywords: Anthropogenic factors, buffer zone, stone cancer, NOX and SOX, social forestry

\section{Introduction}

Taj Mahal, one of the wonders of the world is situated on the banks of Yamuna River in the city of Agra. The construction of this beautiful monument completed in the year 1653, was built by the Mughal Emperor Shah Jahan in memory of his wife Mumtaz. The beauty of Taj Mahal lies not only in the flawless white marble construction but in the feel of love that it has been symbolizing to the world since then. It was declared the UNESCO World Heritage Site in 1980 and have attracts huge number of tourists from all over the world ${ }^{(1)}$. After industries started blooming in neighboring cities, Agra did not stay behind in industrialization and developed quite a large number of industries. Agra is one of the largest centers of leather industries and dairy farms. Also it is known for gems and jewelries as well as marble goods and garment manufacturers ${ }^{(2)}$. While industries bloomed in one part of the place dark clouds of pollution started to darken and surround the atmosphere around Taj Mahal. Soon the white marble was found to lose its glamour and the marble was found to turn yellow followed by darkening in several places. Several studies conducted on such observations converged into the fact that it is kind of disease called 'Stone Cancer', the reason of which was concluded to be acid rain. Reports gathered from all over the world also reported such deterioration of stone monuments, the root cause of which was found to be acid rain ${ }^{(3)}$. The atmosphere is polluted with harmful gases like NOx and Sox as well as chromium and other heavy metals. These pollutants are not only added in the air by industrial activities but also automobile exhausts and sometimes even household activities. An emission of these nitrogen and sulphur compounds reacts with water to produce acids. Such a precipitation is therefore unusually acidic and contains elevated levels of hydrogen ions ( $\mathrm{pH}$ is low). ${ }^{(1)}$ This is called acid rain and it is equally harmful to plants, animals and infrastructure. ${ }^{(9)}$.

Vegetation is known to reduce pollution in an unexpected manner and hence can be used in urban areas and this social forestry is one approach to fight the pollution monsters ${ }^{(4)}(5)$. This approach was undertaken by the government and soon a 'Buffer Zone' was created around Taj Mahal ${ }^{(7)}$. This green cover not only enhanced the beauty of the place but provided a promising remedy of protecting the place and the marble wonder ${ }^{(6)}$. Experiments conducted by us explored another aspect of strategy and it was surprisingly found that the tress that promised to protect the monument, were at risk. The high SPM content accompanied by heavy metal pollutants actually enhanced the infection potential of fungal pathogen. ${ }^{(10)}$ 
Out of a number of various kinds of trees, particular two were found to populate the buffer zone mostly. One was Mahogany and the other was Mimusops elangi, and the percentage of their occurrence was nearly $50-55 \%$.

\section{Source of pathogen}

\section{Materials and Method:}

Infected leaves of Mahogany and Mimusops elangi were collected from the trees that were planted in the buffer zone of Taj Mahal.

\section{Growth media:}

All growth media were purchased from Merck Specialties Pvt. Ltd. (Mumbai, India). All cultures were grown in potato dextrose agar (PDA). Blitox, a common fungicide was used to calculate the inhibition in germination of the fungal spore. Nitric acid was used to create acidic environment around the leaves. The absolute ethanol used here was purchased from Changshu Chemical (Yangyuan, China).

3. Microscopy:

All the leaf sections and spores were visualized under a compound light microscope and Lactophenol cotton blue stain was used.

4. Determination of SPM count and $\mathrm{pH}$ of the leaves collected from Taj Mahal:

The SPM was determined by washing the leaves in sterile distilled water. This water after washing the leaves were subjected to $\mathrm{pH}$ meter and the $\mathrm{pH}$ of the water was determined. The same instrument was used for determining the dissolved oxygen amount, conductivity and SPM count.

5. Checking the infection potential of the pathogen under three in-vitro conditions:

5.1. Fresh clean leaves were incubated with freshly prepared spore suspension in a moist chamber

5.2. Fresh leaves with SPM content were incubated in a moist chamber with freshly prepared spore suspension.

5.3. Fresh leaves were kept in a moist chamber and it contained SPM on its surface. A watch glass was kept inside the moist chamber which contained concentrated nitric acid. Nitric acid is known to be volatile and hence it soon formed an acidic atmosphere inside the moist chamber. This was done to replicate the high NOx concentrations prevailing around Taj Mahal.

6. Slide bio-assay:

Fungicide Blitox was used to observe the change in growth and germination pattern of the pathogen. Two sets of slides were used in which one was a control slide. Blitox was absent from the control slide.

\section{Results}

1. The isolated leaf spots gave rise to cottony growth of fungal pathogen after an incubation time of about 14days. Spore suspension prepared from the above mentioned observed spores gave rise similar leaf spot disease in fresh leaves. This proves Koch's Postulates and thereby the pathogen was isolated.

2. Microscope studies have shown the infection thread to extend along the leaf lamina and fungal growth on underlying mesophyll cells. Two separate species were found to infect the two different leaves. While the mahogany leaves were found to be infected by a pathogen producing elongated, rod shaped spores; the Mimusops elangi was infected by small, circular spore producing pathogen and also the former. It was also observed that the spores gave a reddish appearance on the agar slant.

3. Studies reveal that similar spot disease has been found in mahogany leaves and the causative organisms were similar in appearance to Mycospharella. The other organism was very similar in appearance to Cladosporium. ${ }^{(12)(14)}$

4. The lengths of the elongated spores were found to be $1.5 \mu \mathrm{m}$ on an average and breadth of about $0.25 \mu \mathrm{m}$.

5. The three setup gave interesting results. The one without SPM and acid vapors produced only $15 \%$ infection while the one with SPM content showed about $45 \%$ infection. It was seen further that the one with both SPM and acid vapors produced almost had the entire leaf infected.

6. The percentage of infection was found to be inhibited by the Blitox, and in one experimental it was found to completely inhibit spore germination in the slide bio-assay.

\section{Discussion:}

Studies conducted on various plants have revealed that SO4 induce foliar injury that develops into necrotic lesions and can hamper the net assimilation of plants (Katz, 1949; Thomas, 1951; Weinstein and Mc Cune, 1970)

In fumigation studies carried on perennial weeds in the United States have indicated plant injury showing leaf discoloration and associated cell collapse and necrosis (Benedict and Breen ,1955) 
In one experiment exposure of Mimusops elangi to various levels of NO2 brought about decrease in shoot legth, fresh and dry weights, ascorbic acid levels which results in susceptibility to fungal infections ((Tiwari and Bansal, 1993)

Various morphological, physiological and biochemical responses including decrease in metabolic rate and cellular functions was observed as a result of phyto-toxicity of SO2 in Cicer arietinum (Ferguson et al., 1978)

The results obtained above can be compared with the reported works and it can be said that high SPM count coupled with the presence of NOX and SOX in the atmosphere leads to leaf injury as observed. This injury might have triggered the infection process in these leaves.

Blitox (copper oxychloride) was found to inhibit the growth of Cladosporium oxysporum in an experiment carried out in field applications of seedling plants (S. L. Willingham, K.G Pegg, A. W Cooke, D. Peasley, R. Mclennan, P. W. B. Langdon ,2002). White oil emulsion and Malachite green mixed with Copper oxychloride (BLITOX) gave satisfactory control on banana leaf spot disease caused by Mycospharella musicola in Queensland, Australia (Pont W, 1960, Journal of Agricultural Sciences).

This significant effect of Copper oxychloride was observed in the experiments carried out in the lab and it was found to reduce germination for both the pathogens. This result when compared with the reported works gives a simmilarity

Road side plants therefore, if protected with antifungal dusting, may encourage urban forestry. Also it can be concluded that relatively less important timber producing trees, if protected by antifungal spraying may restore the social forest belt around the Taj Mahal and protect the monument in furure.

\section{References:}

[1]. Wells, John C. (1990). Legacy of the Indian Khilafat movement. Longman pronunciation dictionary. Harlow, England

[2]. Justice Markendey Ketju. (2002). Environment and Industrialization .Environment and pollution control, Judicial activism.

[3]. W.G. Wilson (2011). Constructed Climates: A primer on urban environments. Chicago: University of Chicago Press.

[4]. Nowak, D. (2000). Tree Species Selection, Design, and Management to Improve Air Quality Construction Technology. Annual meeting proceedings of the American Society of Landscape Architects

[5]. McPherson, E. G. \& Simpson, J. R. (2000). Reducing Air Pollution through Urban Forestry. Proceedings of the 48th meeting of California Pest Council

[6]. McPherson, E. G., Simpson, J. R. \& Scott, K. (2002). Actualizing Microclimate and Air Quality Benefits with Parking Lot Shade Ordinances. Wetter und Leben 4: 9

[7]. K. C. and Likens, G. E. (2006). "Acid rain" pp. 1549-1561

[8]. W. N. Rom and S. Markowitz (2006.). Environmental and Occupational Medicine. Lippincott-Raven Publ., Philadelphia.

[9]. Winstanley, Derek; Lackey, Robert T.; Warnick, Walter L.; Malanchuk, John (1998). "Acid rain: Science and policy making". Environmental Science \& Policy

[10]. Anil K.Raina,Singh C.D, Deepica.R and Kumar. A (2004). Effect of vehicular exhaust on some trees in Jammu- 1.indian .J.Environ.\& Ecoplan . Vol 18 (1) : pp $149-152$.

[11]. Boralkar, D.B and Chaphekar, S.B (1989). Nature of sensitivity of plant species to sulphur dioxide Geobios 16: 115-116.

[12]. Agarwal, S.K (1991) Pollution Ecology, Himanshu Publication, Udaipur.

[13]. Rivas, S. \& Thomas C.M., (2005). Molecular interactions between tomato and the leaf mold pathogen: Cladosporium fulvum. Annual Review of Phytopathology 43: 395-436.

[14]. Orton E. S., Sian Deller S. \& Brown J. K. M. (2011). "Mycosphaerella graminicola: from genomics to disease control". 12(5): 413424

[15]. Domsch, K.H., W. Gams, and T.H. Anderson. (1980). Compendium of soil fungi. Academic Press, London, UK.

[16]. Sivanesan, A., and Gibson, I. A. S. (1976). CMI Descriptions of Pathogenic Fungi and Bacteria: Commonwealth Mycological Institute, Kew, Surrey, England.

\section{Tables and figures:}

Table1: showing the following parameters determined for the leaves collected from Taj Mahal

\begin{tabular}{|c|c|c|c|}
\hline Name & Electrical conductivity $(\mu \mathrm{s})$ & SPM (in mg) & pH \\
\hline Mahogany & 4.302 & $\mathbf{6 7 . 3}$ & 5.568 \\
\hline Mimusops elangi & $\mathbf{3 5 . 8 0}$ & $\mathbf{1 2 0 . 6}$ & $\mathbf{5 . 9 6 5}$ \\
\hline
\end{tabular}

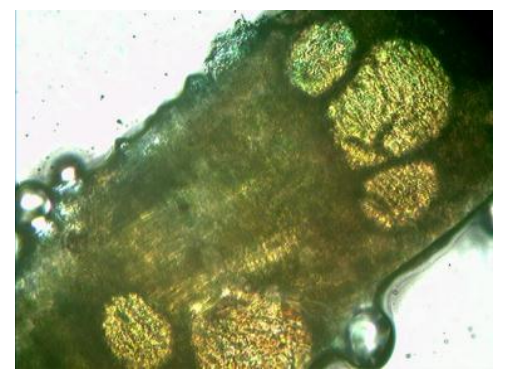

(a)

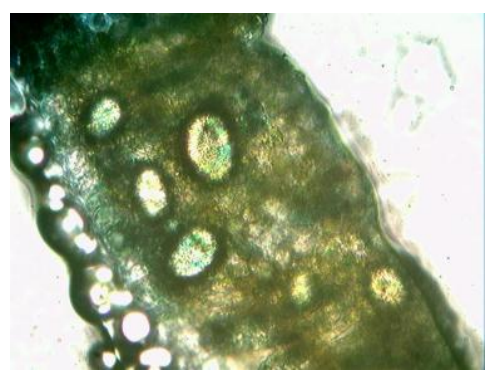

(b)

Fig1.(a) and (b) shows growth of fungal pathogen inside the cells of the leaf 

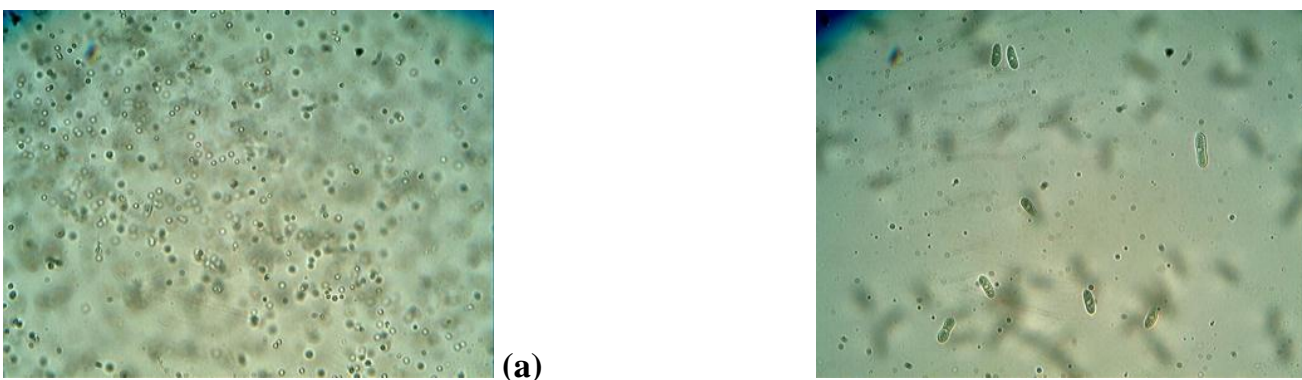

(b)

Fig 2: (a) shows Cladosporium sp. And (b) shows Mycospharella sp.

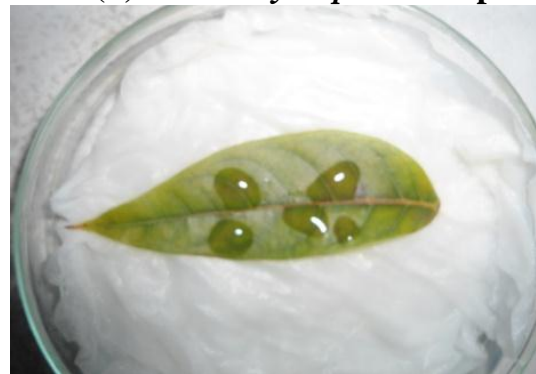

Fig 3: low infection in absence of SPM and acid vapors

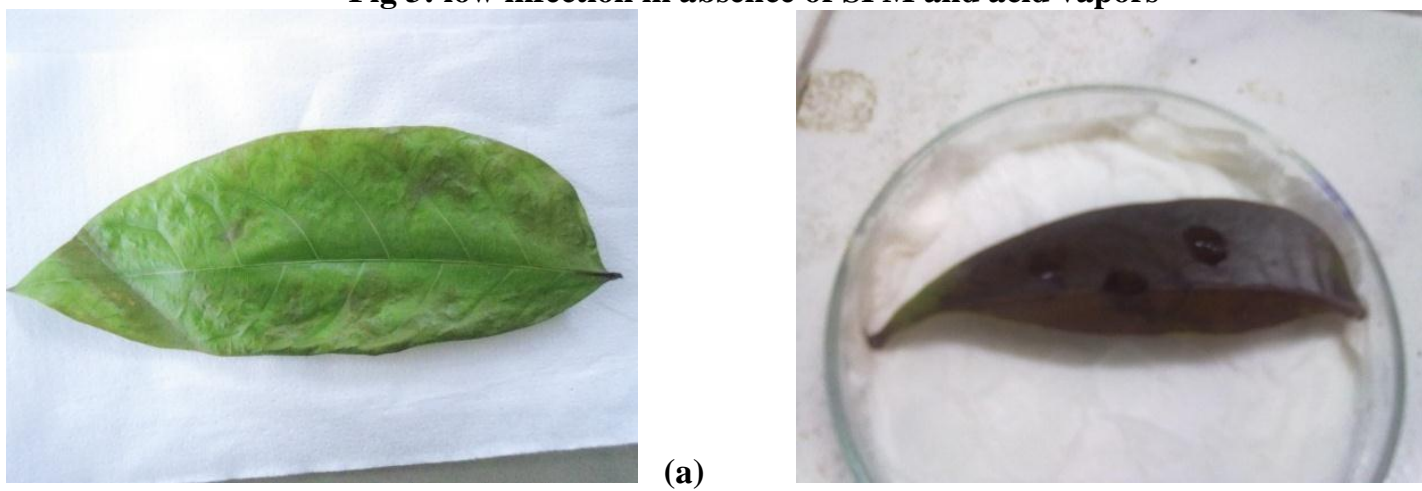

(b)

Fig 4: comparison showing greater infection(b) in presence of SPM \& acid vapors

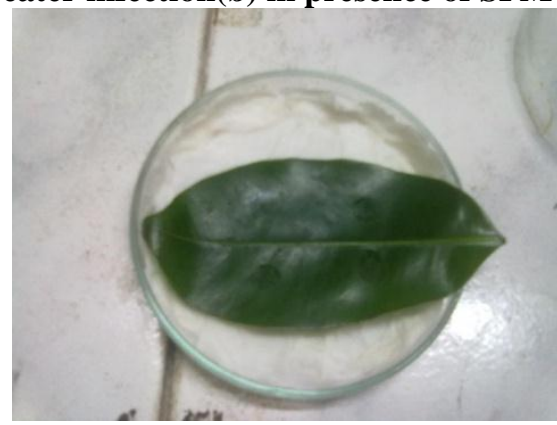

Fig 5: Absence in infection in absence of SPM and acid vapors
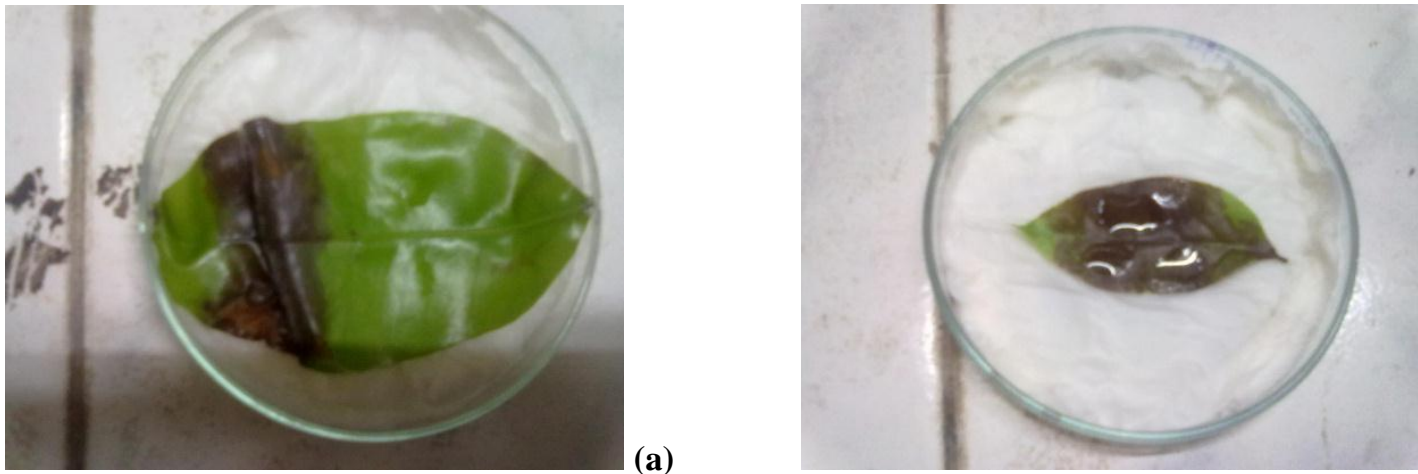

(b) in presence of SPM \& acid vapors

Fig 6:comparison showing greater infection (b) in presence of SPM \& acid vapors 


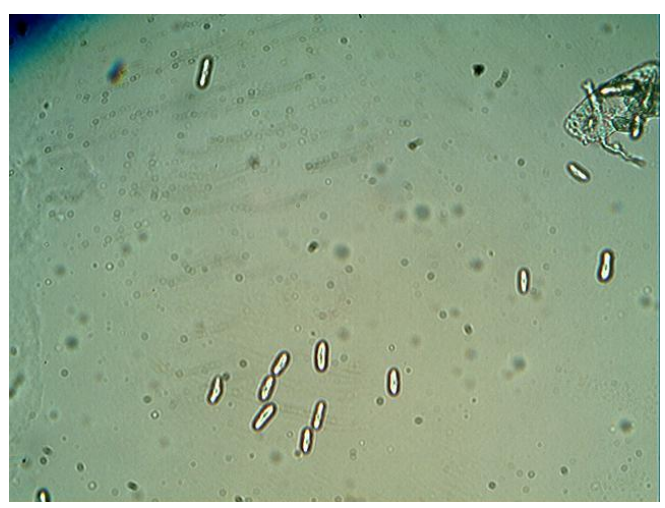

Fig 7: Absence of germination in presence of fungicide Blitox 